\title{
Poly(A) addition during maturation of frog oocytes: distinct nuclear and cytoplasmic activities and regulation by the sequence UUUUUAU
}

\author{
Catherine A. Fox ${ }^{1}$, Michael D. Sheets ${ }^{1,2}$, and Marvin P. Wickens ${ }^{1,2}$ \\ ${ }^{1}$ Department of Biochemistry and ${ }^{2}$ Molecular Biology Program, College of Agriculture and Life Sciences and the Graduate \\ School, University of Wisconsin, Madison, Wisconsin 53706 USA
}

\begin{abstract}
In frog oocytes, certain maternal mRNAs receive poly $(A)$ in the cytoplasm during progesterone-induced maturation. To analyze this reaction and to compare it to poly(A) addition in the nucleus, we injected short, synthetic RNA substrates into Xenopus oocytes. These RNAs contain only portions of the $3^{\prime}$-untranslated regions of appropriate mRNAs and end at the natural poly(A) site. We demonstrate that the nuclear and maturation-specific polyadenylation activities are distinct in substrate specificity and subcellular location. The sequence AAUAAA, contained in virtually all pre-mRNAs, is necessary for both activities. A second sequence element, UUUUUAU, activates poly(A) addition during maturation. UUUUUAU and AAUAAA are both necessary and virtually sufficient for maturation-specific polyadenylation: Poly $(A)$ tails of between 50 and 300 nucleotides are added during maturation to RNAs containing both sequences but not to RNAs that lack either sequence. Before maturation, RNAs that contain AAUAAA are extended by just 10 nucleotides, presumably adenosines. The maturation-specific activity first appears within $1 \mathrm{hr}$ of the time the nucleus breaks down but apparently does not require a nuclear component, as it is unaffected by enucleation. These observations, combined with those of others, lead us to speculate that polyadenylation may be responsible for the translational activation of a family of mRNAs essential for maturation.
\end{abstract}

[Key Words: Polyadenylation; poly(A); regulation; oocytes; maturation]

Received August 10 1989; revised version accepted October 24, 1989.

Most mRNAs in animal cells possess a 3 '-terminal tract of 20-250 adenosine residues [poly(A)]. This poly(A) tail initially is added in the nucleus, post-transcriptionally. After transport to the cytoplasm, the poly(A) segment can be lengthened or shortened (for review, see Lewin 1980).

Polyadenylation in a cell-free nuclear extract and in the nucleus is intimately coupled to a cleavage reaction in which a specific phosphodiester bond in the mRNA precursor is broken (Nevins and Darnell 1978; Gick et al. 1986; Moore et al. 1986; Sheets et al. 1987). Poly(A) is then added, one nucleotide at a time (Moore and Sharp 1985), to the new $3^{\prime}$ end. Addition of the poly(A) tail occurs in two discrete phases (Sheets and Wickens 1989; $\mathrm{V}$. Bardwell and $\mathrm{M}$. Wickens, in press). In the first phase, the addition of each adenosine requires the highly conserved sequence AAUAAA, located within 30 nucleotides of the poly(A) tail of virtually all eukaryotic mRNAs. In the second phase, addition of A residues depends on the oligo(A) segment already synthesized, rather than on AAUAAA.

In vitro, mRNA-specific poly(A) addition requires at least two components: a poly(A) polymerase and a specificity factor /Christofori and Keller 1988, 1989; McDevitt et al. 1988; Takagaki et al. 1988; Bardwell et al. 1990). In the absence of the specificity factor, partially purified HeLa cell polymerase is active on many RNA substrates, including tRNA and small oligonucleotides. In the presence of specificity factor, however, only RNAs with AAUAAA receive poly(A) (for review, see $M$. Wickens, in prep.).

Cytoplasmic changes in poly(A) tail length can be regulated. For example, in eggs of many animal species, at or near the time of fertilization, certain mRNAs receive poly (A), whereas others have their poly(A) tails removed (e.g., Rosenthal et al. 1983; Bachvarova et al. 1985; Dworkin and Dworkin-Rastl 1985; Rosenthal and Ruderman 1987; Paynton et al. 1988). These changes generally correlate with translational activity: increases in poly $(A)$ tail length often accompany increases in translation, whereas deadenylation is correlated with decreased translation (Rosenthal et al. 1983; Dworkin and Dworkin-Rastl 1985; Dworkin et al. 1985; Huarte et al. 1987; Rosenthal and Ruderman 1987; Hyman and Wor- 
mington 1988; Strickland et al. 1988; McGrew et al. 1989|. These general correlations are not absolute, however; with some maternal mRNAs, poly(A) tail length either does not change, or is even reduced, during translational activation (e.g., Ruderman et al. 1979).

In Xenopus, cytoplasmic changes in poly(A) tail length have been extensively documented during oocyte 'maturation' (e.g., Colot and Rosbash 1982; Dworkin and Dworkin-Rastl 1985). Xenopus oocytes advance from first meiotic prophase to second meiotic metaphase in response to progesterone. During this single cell cycle, the nuclear envelope breaks down and the length of poly(A), present on specific mRNAs, changes.

In this report we inject short synthetic RNAs to examine poly(A) addition both in the oocyte nucleus and in the cytoplasm during maturation. These short RNA substrates contain only portions of the 3 '-untranslated regions either of SV40 virion protein mRNAs or Xenopus D7 mRNA. The maturation of SV40 virion protein mRNAs has been widely used to examine the mRNA processing apparatus of the oocyte nucleus $\{$ e.g., De Robertis and Mertz 1977; Wickens and Gurdon 1983; Fradin et al. 1984). D7 mRNA was identified by Dworkin and Dworkin-Rastl (1985) as an exclusively maternal mRNA that is recruited onto polyribosomes early in development. Its poly(A) tail is lengthened during oocyte maturation. D7 protein is required for efficient maturation (Smith et al. 1988).

By injecting variant D7 and SV40 RNAs into oocytes, we analyze the activities that add poly(A) in the nucleus and those that add poly(A) during maturation and compare their sequence-specificities and subcellular locations. In light of our findings, we discuss possible mechanisms for cytoplasmic poly(A) addition and its regulation, and a critical role that poly $(\mathrm{A})$ addition may play in the maturation of frog oocytes.

\section{Results}

\section{Substrates}

RNAs used in this report are derived from either the Xenopus D7 gene (Dworkin and Dworkin-Rastl 1985; Smith et al. 1988) or the virion protein gene of SV40. RNAs were prepared by transcription in vitro using phage RNA polymerases and cloned DNA templates (Melton et al. 1984). The RNAs are short, ranging from 65 to 245 nucleotides; in general, they contain only portions of the 3 '-untranslated regions of the mRNAs. The particular nucleotides present in any given RNA are indicated by designating the natural poly $(\mathrm{A})$ addition site as +1 . For example, the $5^{\prime}$ end of the SV40 sequences present in $-141 /+1$ SV40 RNA lies 141 nucleotides before the poly(A) site. All RNAs are capped with $\mathrm{m}^{7} \mathrm{GpppG}$.

\section{Poly (A) addition in the oocyte nucleus}

Previous work has shown that after injection of SV40 DNA into the oocyte nucleus, the primary transcripts undergo coupled cleavage and polyadenylation reactions
(Wickens and Gurdon 1983). To examine polyadenylation in the absence of cleavage and transcription, we injected SV40 RNAs ending at the poly(A) site into the nucleus. Labeled -141/-1 RNA was injected into the oocyte nucleus. At various times thereafter, oocytes were homogenized, and the RNA recovered by phenol extraction and ethanol precipitation. The length of the labeled RNA in each sample was determined by gel electrophoresis and autoradiography. In all of the experiments described in this report, oocytes were analyzed individually to assess any oocyte-to-oocyte variation and to correct for failure to inject into the nucleus (see Materials and methods/. In this particular experiment, data are presented from a single oocyte for each time point (Fig. 1).

The injected RNA lengthens progressively during a 30-min incubation (Fig. 1A, lanes 1-4). Both the fraction of molecules that receive any poly $(A)$ and the average length of poly(A) present vary as a function of time. By $30 \mathrm{~min}$, most of the RNA has been lengthened by $\sim 250$ nucleotides (Fig, 1A, lane 4 versus lane 1).

The increase in length is the result of the addition of poly(A) (Fig. 1A, lanes 5-7). RNAs prepared $30 \mathrm{~min}$ after injection (lane 5 ) were fractionated by oligo(dT)-cellulose chromatography. The lengthened RNAs are retained by the column (lane 7), whereas RNAs that are the same length as the substrate are not (lane 6). We conclude that, by $30 \mathrm{~min}$, a poly $(\mathrm{A})$ tail has been added to most of the RNAs that were injected. Thus, a short segment of RNA is sufficient for nuclear polyadenylation.

To identify sequences that direct nuclear polyadenylation, we injected $-58 /+7$ SV40 RNAs containing either the canonical, highly conserved AAUAAA sequence, or

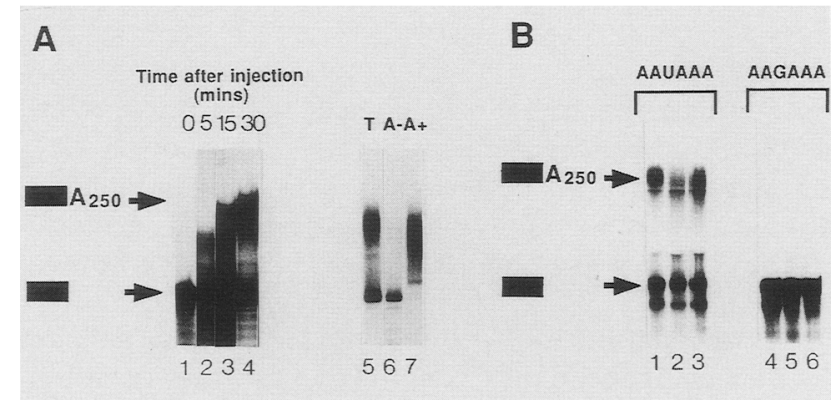

Figure 1. Addition of poly $(\mathrm{A})$ in the oocyte nucleus. $(A) \mathrm{Ki}$ netics of nuclear polyadenylation and oligo(dT)-cellulose chromatography. In this and all subsequent figures, black boxes are used to represent the non-poly $(A)$ body of the injected RNA. (Lanes 1-4) - 141/-1 SV40 RNA was injected into oocyte nuclei and incubated for the times indicated. Each lane contains RNA from one oocyte. (Lanes 5-7) - 141/-1 SV40 RNA was injected into oocyte nuclei, incubated for $30 \mathrm{~min}$, and fractionated by oligo(dT)-cellulose chromatography. (Lane 5) Unfractionated, total RNA (T); (lane 6) RNA that does not bind (A-); (lane 7) RNA that does bind $(A+)$. (B) Sequence specificity of nuclear polyadenylation. - 58/ + 7 SV40 RNA containing either AAUAAA (lanes 1-3) or AAGAAA (lanes 4-6) was injected into oocyte nuclei and incubated for $30 \mathrm{~min}$. Each lane contains RNA from one oocyte. 
a single point mutation to AAGAAA (Fig. 1B). RNA was prepared $30 \mathrm{~min}$ after injection and analyzed by gel electrophoresis. Three oocytes injected with each RNA are shown. As expected, the injected AAUAAA-containing RNA receives a poly(A) tail of $\sim 250$ nucleotides during incubation in the nucleus (Fig. 1B, lanes 1-3). In contrast, the AAGAAA-containing RNA is not lengthened detectably (lanes 4-6). Thus, AAUAAA is required for poly(A) addition in the nucleus, as it is in a HeLa cell nuclear extract (e.g., Sheets and Wickens 1989).

\section{AAUAAA-dependent poly $(A)$ addition in nucleus versus cytoplasm}

To determine whether the AAUAAA-dependent activity is present in the cytoplasm, we injected $-58 /+7$ SV40 RNA into that compartment (Fig. 2A, lanes 1 and 2). As a control, we injected the same RNA into the nucleus (lanes 3 and 4). Two oocytes from both types of injection are shown. RNA injected into the nucleus receives poly(A) (lanes 3 and 4), whereas RNA injected into the cytoplasm does not (lanes 1 and 2). Rather, RNA injected into the cytoplasm is inert, but stable, during a $2.5-\mathrm{hr}$ incubation.

\section{Extension of oligo(A) tracts in nucleus versus cytoplasm}

In the second phase of polyadenylation in vitro (see introductory section), an oligo(A) primer is extended, independent of the AAUAAA sequence (Sheets and Wickens 1989). To evaluate whether polyadenylation in the oo-

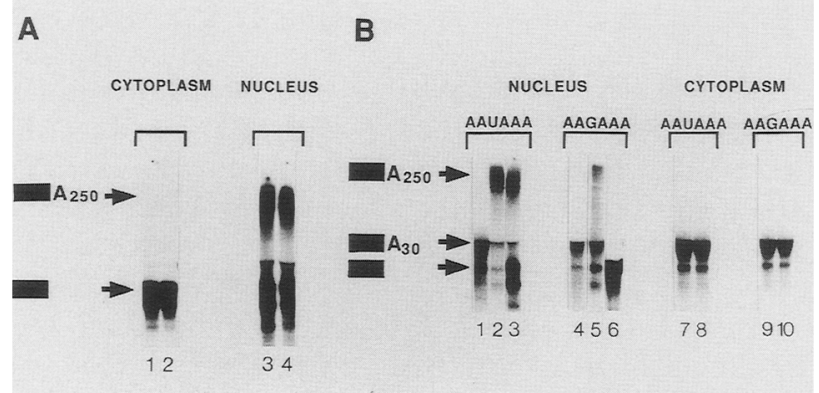

Figure 2. Poly(A) addition in nucleus versus cytoplasm. (A) AAUAAA-dependent polyadenylation in nucleus versus cytoplasm. $-58 /+7$ SV40 RNA containing AAUAAA was injected into either oocyte cytoplasms and incubated for 2.5 hours (lanes 1 and 2) or into oocyte nuclei and incubated for $30 \mathrm{~min}$ (lanes 3 and 4). Each lane contains RNA from one oocyte. (B) Oligo(A) extension in nucleus versus cytoplasm. Each lane contains RNA from one oocyte. (Lane 1) Noninjected $-58 /+7$ SV40 RNA containing AAUAAA and a $3^{\prime}$ oligo(A) tract; (lane 2) $-58 /+7$ SV40 RNA containing AAUAAA and a $3^{\prime}$ oligo(A) tract was injected into oocyte nuclei and incubated for $30 \mathrm{~min}$; (lane 3) -58/+ 7 SV40 RNA containing AAUAAA was injected into oocyte nuclei and incubated for $30 \mathrm{~min}$. (Lanes 4-6) are analogous to lanes 1-3, except that RNA contains AAGAAA. (Lanes 7-8) - 58/ + 7 SV40 RNA containing AAUAAA and a $3^{\prime}$ oligo(A) tract was injected into oocyte cytoplasms and incubated for $2.5 \mathrm{hr}$; (lanes 9-10) identical to lanes 7 and 8, except that the injected $-58 /+7$ SV40 RNA contains AAGAAA. cyte nucleus proceeds by a similar mechanism, we injected $-58 /+7$ RNAs containing a $3^{\prime}$ terminal oligo(A) tail of $\sim 30$ nucleotides into the nucleus (Fig. 2B). These RNAs contained either AAUAAA or AAGAAA.

The oligo(A) tract on the AAUAAA-containing RNA is extended into full-length poly(A) (Fig. 2B, lane 1 versus lane 2). The reaction is at least as efficient as that observed with the same RNA without any oligo(A) tract (Fig. 2B, lane 3). This oligo(A) extension reaction is partially independent of AAUAAA; RNAs containing AAGAAA, which do not support polyadenylation at all without an oligo(A) tract (lane 6), do support polyadenylation if an oligo(A) tract is present (Fig. 2B, lane 4 versus lane 5). Although the oligo(A) segment clearly enhances polyadenylation of the AAGAAA-containing RNA /cf. lanes 5 and 6), it does not restore polyadenylation to the level observed with an identical RNA carrying AAUAAA (cf. lanes 5 and 2). Nevertheless, by analogy to the in vitro data from HeLa cells, we infer that, nuclear polyadenylation probably occurs in two phases in the oocyte.

The oligo(A) extension activity, like the activity that requires AAUAAA, is exclusively nuclear. After injection into the cytoplasm, $-58 /+7$ SV40 RNAs with an oligo(A) segment undergo no detectable reaction, whether or not they contain AAUAAA (Fig. 2B, lanes $7-10)$.

\section{Poly $(A)$ addition during maturation}

During oocyte maturation, poly(A) is added in the cytoplasm to certain maternal mRNAs, including D7 mRNA (Dworkin and Dworkin-Rastl 1985). To assess whether these cytoplasmic events could be assayed using synthetic RNAs, we injected $-242 /+1$ D7 RNA into the oocyte cytoplasm. Oocytes were induced to mature with progesterone. After maturation was complete, RNAs were analyzed by gel electrophoresis. As a control, some injected oocytes were incubated without progesterone for the same length of time.

Synthetic D7 RNA injected into oocytes receives poly(A) during oocyte maturation (Fig. 3A). The injected RNA (lane 1) is lengthened by $10-150$ nucleotides during maturation (lanes 4 and 5). This lengthening is attributable to the addition of poly(A), as judged by oligo(dT)-cellulose chromatography (lanes 6 and 7). In the absence of progesterone, no long poly $(\mathrm{A})$ is observed (Fig. 3A, lanes 2 and 3 versus lane 1). Thus, the maturation-specific polyadenylation reaction is mimicked using this short synthetic RNA containing only the $3^{\prime}$ untranslated region of D7 mRNA.

To test whether the polyadenylation reaction that occurs during maturation is sequence-specific, we injected $-141 /-1$ SV40 RNA into the cytoplasm, then treated the oocytes with progesterone (Fig. 3B). SV40 RNA, unlike D7 RNA, does not receive poly(A), either with or without progesterone treatment (lanes 1-5). We conclude from these data that the activity responsible for the polyadenylation of $\mathrm{D} 7$ during maturation is specific for sequences present in the D7 RNA. 


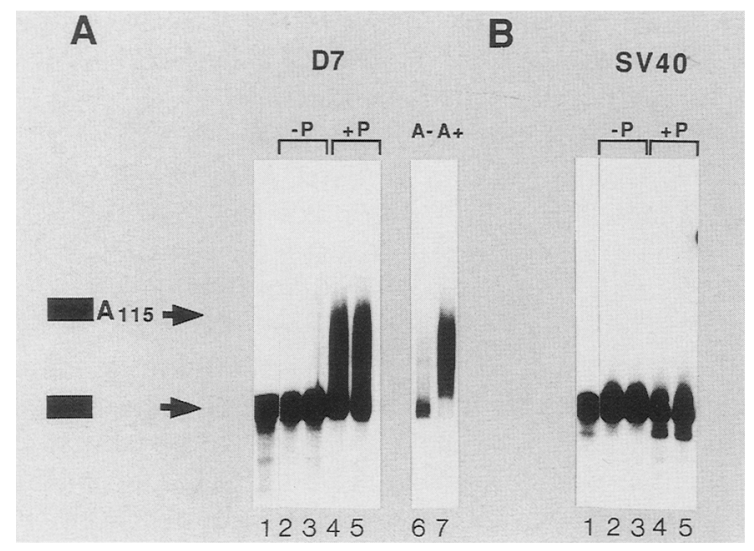

Figure 3. Poly $(A)$ addition during maturation. Each lane contains RNA from one oocyte. $(A)$ Synthetic D7 RNA receives poly(A) during maturation. $-242 /+1$ D7 RNA was injected into oocyte cytoplasms and incubated for $12 \mathrm{hr}$ in the absence (lanes 2 and $3,-\mathrm{P}$ ) or presence (lanes 4 and $5,+\mathrm{P}$ ) of progesterone. (Lane 1) RNA that was not injected into the oocyte; (Lanes 6 and 7) RNA from an oocyte injected with $-242 /+1$ D7 RNA and treated with progesterone was fractionated by oligo(dT)-cellulose chromatography; (Lane 6) RNA that did not bind $(\mathrm{A}-)_{\text {; }}$ (lane 7$) \mathrm{RNA}$ that did bind $(\mathrm{A}+) .(\mathrm{B})$ Polyadenylation during maturation is sequence-specific. $-141 /-1$ SV40 RNA was injected into oocyte cytoplasms and incubated for 12 $\mathrm{hr}$ in the absence (lanes 2 and $3,-\mathrm{P}$ ) or presence (lanes 4 and 5 , $+\mathrm{P}$ ) of progesterone. Lane 1 contains RNA that was not injected into the oocyte.

\section{Nuclear polyadenylation: SV40 versus D7}

To determine whether D7 RNA is a substrate for the nuclear activity, we injected it into the nucleus. As a control, SV40 RNA was injected in parallel. After 30 min, RNA was prepared and analyzed by electrophoresis (Fig. 4). The SV40 RNA is efficiently polyadenylated (lanes 1 and 2), whereas the D7 RNA is not (lanes 3 and 4). Thus, the nuclear polyadenylation activity does not recognize D7 RNA as a substrate. Therefore, we conclude that the nuclear and maturation-specific polyadenylation activities are distinct with respect to sequence specificity.

D7 mRNA contains AAUAUA rather than the canonical AAUAAA (Smith et al. 1988). This presumably underlies its failure to receive poly(A) in the nucleus, because changing AAUAAA to AAUAUA in SV40 RNA reduces nuclear polyadenylation dramatically (not shown; see Discussion).

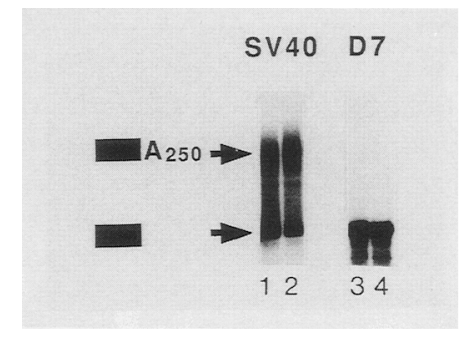

Figure 4. Nuclear polyadenylation: SV40 versus D7. $-141 /-$ 1 SV40 RNA (lanes 1 and 2) or $-242 /+1$ D7 RNA (lanes 3 and 4) was injected into oocyte nuclei and incubated for $30 \mathrm{~min}$. Each lane contains RNA from one oocyte.

The sequence UUUUUAU confers maturation-specific polyadenylation on SV4O RNA

Several maternal mRNAs that receive poly(A) during maturation contain UUUUUAU, or a closely related sequence, upstream of AAUAAA (Table 1; McGrew et al. 1989). To determine whether this sequence is responsible for maturation-specific polyadenylation, we inserted it into $-141 /-1$ SV40 RNA upstream of AAUAAA. The sequences of the relevant portion of this RNA and of the natural SV40 RNA are shown in Figure 5A. The two RNAs differ by only 3 nucleotides: a CCAUUAU sequence in SV40 has been converted to UUUUUAU.

In the absence of progesterone, the UUUUUAU-containing RNA does not receive poly|A) (Fig. 5B, lanes 2 and 3). In contrast, in the presence of progesterone, it is lengthened by $10-100$ nucleotides (Fig. 5B, lanes 4 and 5). This progesterone-induced lengthening is the result of the addition of poly $(\mathrm{A})$ as judged by treatment with oligo(dT) and RNase H (not shown). RNA lacking UUUUUAU is not lengthened, either with or without progesterone (Fig. 5B, lanes 6-10). We infer that the heptanucleotide UUUUUAU is sufficient to confer activity on a substrate that is otherwise inert during maturation.

\section{Point mutations in AAUAAA abolish maturation-} specific polyadenylation

To test whether AAUAAA is required for polyadenylation during maturation, we prepared variant SV40 RNAs in which AAUAAA was changed either to AAUAUA or AAGAAA (for sequences, see Fig. 6A). These RNAs each differ from the natural SV40 sequence

Table 1. Xenopus $m R N A s$ that receive poly(A) during early development

\begin{tabular}{|c|c|}
\hline mRNA & Sequence \\
\hline D7 & g c c u u c UUUUUA c a u a u u a g c UUUUUAUc a caAAUAUAaua cua auuua cuug a auguuauuuguuaacc-poly(A) \\
\hline G10 & 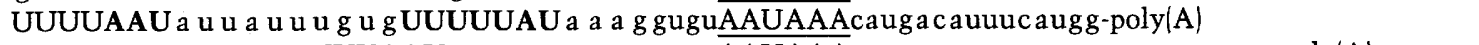 \\
\hline B4 & g u a a a c u g g UUUUUUAAU g u u a a u u c uauaAAUAAAgua a gua auuguuuuuuuuuuucuu-poly(A) \\
\hline $\mathrm{H} 4$ & u u u uUUUUUAU a u a a u u g u a a c uuuuaAAUAAAacuuucuccauu-poly(A) \\
\hline
\end{tabular}

Sequences are taken from the following publications: D7, Smith et al. (1988); G10, McGrew et al. (1989); B4, Smith et al. (1988). The sequence of H4 mRNAs (Dworkin et al. 1985) was determined by the authors (see Methods) and is reported here for the first time. A similar table has previously been presented by McGrew et al. (1989). 
A

UAAUUUUUAUAAGCUGCA AUA A ACAAGUUAACAACCUCUAG $O H$

UAACCAUUAUAAGCUGCAAUAAACAAGUUAACAACCUCUAG ${ }_{O H}$

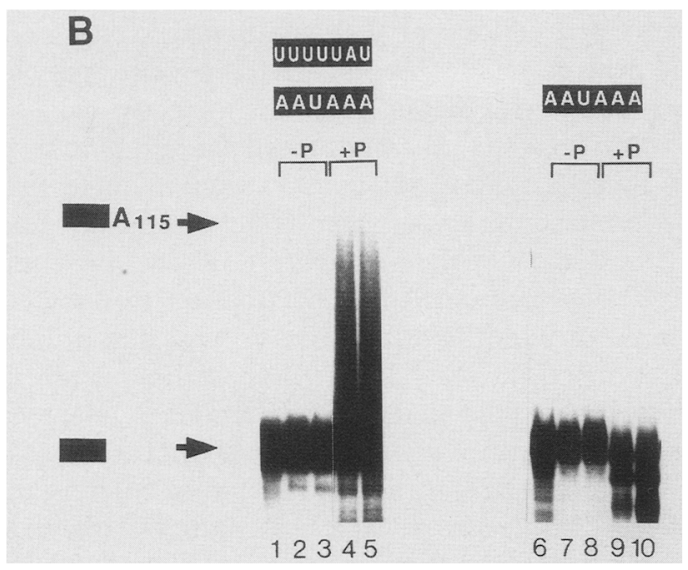

Figure 5. UUUUUAU confers maturation-specific polyadenylation. (A) Sequences of injected RNAs. The sequence of the $3^{\prime}$ terminal 41 nucleotides of the RNAs used in this experiment are shown. Each is derived from a $-141 /-1$ SV40 RNA /thus, the 100 nucleotides upstream of the sequences provided are identical in each RNA). Black boxes highlight the positions of UUUUUAU and AAUAAA. (B) Results. Each lane contains RNA from one oocyte. RNA was injected into the cytoplasm. Oocytes were then incubated for $8 \mathrm{hr}$ in either the presence $(+\mathrm{P})$ or absence $(-\mathrm{P})$ of progesterone. In lanes 1-5, the injected RNA contains both UUUUUAU and AAUAAA (upper sequence). (Lane 1) RNA that has not been injected; (lanes 2 and 3) RNA injected, no progesterone added; (lanes 4 and 5) RNA injected, progesterone added. In lanes 6-10, the injected RNA contains only AAUAAA (lower sequence). (Lane 6) RNA that was not injected; (lanes 7 and 8) RNA injected, no progesterone added; (lanes 9 and 10) RNA injected, progesterone added.

used in Figure 5; 5 nucleotides lying between AAUAAA and UUUUUAU have been changed to facilitate cloning.

As expected, the RNA containing UUUUUAU receives long poly(A) during maturation (Fig. 6B, lanes $1-5)$. These data confirm that UUUUUAU is sufficient to confer activity. Polyadenylation of the UUUUUAUcontaining RNA analyzed here is more efficient than with the comparable RNA in Figure 5A. We infer that the precise sequence context of UUUUUAU and AAUAAA can influence the efficiency of the reaction.

Mutation of AAUAAA to either AAUAUA or AAGAAA abolishes polyadenylation during maturation (Fig. 6B, lanes 9 and 10, 14 and 15). Thus, AAUAAA, like UUUUUAU, is required for polyadenylation during maturation.

In the absence of progesterone, RNA containing AAUAAA and UUUUUAU is lengthened by $\sim 10 \mathrm{nu}-$ cleotides (Fig. 6B, lane 1 versus lanes 2 and 3). The syn- thesis of these slightly longer RNAs is reduced by the AAGAAA and AAUAUA mutations (Fig. 6B; lanes 6-8, $11-13)$. We stiongly suspect that the 10 nucleotides are adenosine, as their formation requires AAUAAA, but we have not confirmed this directly. The presumptive oligoadenylation is detected most convincingly with shorter substrates (e.g., Fig. 7 below), because the $10 \mathrm{nu}$ cleotides then constitute a greater fraction of the RNA's length.

\section{AAUAAA and UUUUUAU are virtually sufficient for polyadenylation during maturation}

If UUUUUAU and AAUAAA are necessary and sufficient for polyadenylation during maturation, then adeno-
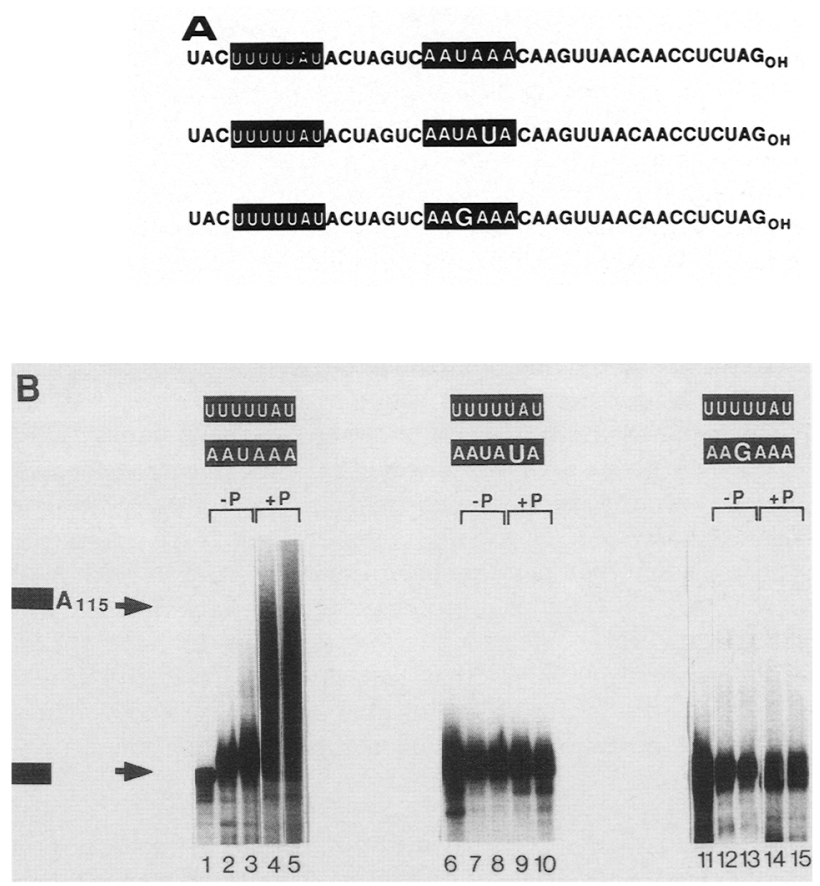

Figure 6. Point mutations in AAUAAA abolish maturationspecific polyadenylation. (A) Sequences of injected RNAs. The sequences of the $3^{\prime}$ terminal 41 nucleotides of the RNAs used in this experiments are shown. Each is derived from a -141/ 1 SV40 RNA. Black boxes highlight the positions of UUUUUAU and AAUAAA or its derivatives. Five nucleotides between AAUAAA and UUUUUAU also have been changed relative to wild-type SV40 (as in Fig. 5) to generate a restriction site. $(B)$ Results. RNA was injected into the cytoplasm. Each lane contains RNA from one oocyte. In lanes 1-5, -141/-1 SV40 RNA containing both AAUAAA and UUUUUAU was used (top sequence). (Lane 1) RNA that has not been injected; (lanes 2 and 3) RNA injected, no progesterone added; (lanes 4 and 5) RNA injected, progesterone added. In lanes 6-10, RNA containing AAUAUA and UUUUUAU was used (second sequence). (Lane 6) RNA that has not been injected; (lanes 7 and 8) RNA injected, no progesterone added; (lanes 9 and 10) RNA injected, progesterone added. In lanes 11-15, RNA containing AAGAAA and UUUUUAU was used (third sequence). (Lane 11) RNA that has not been injected; (lanes 12 and 13) RNA injected, no progesterone added; (lanes 14 and 15) RNA injected, progesterone added. 
A

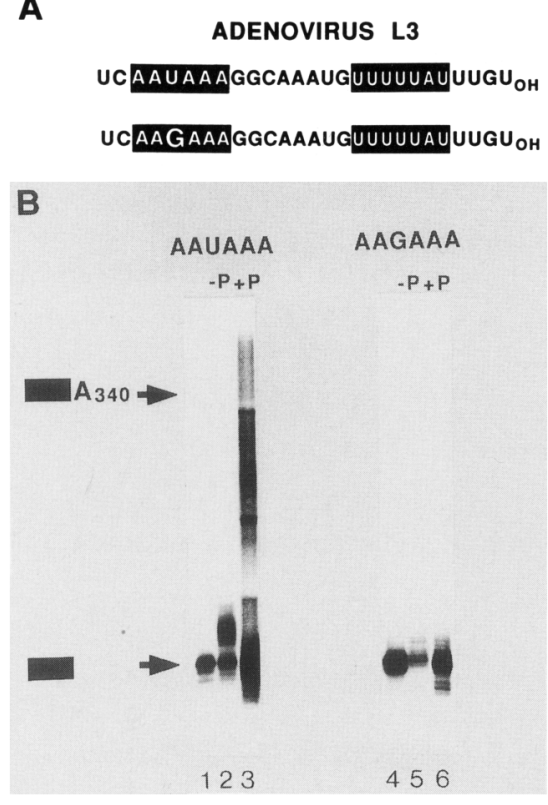

Figure 7. AAUAAA and UUUUUAU are virtually sufficient for polyadenylation during maturation. $(A)$ Sequences. The sequences of the $3^{\prime}$ terminal 27 nucleotides of the $-41 /-1$ adenovirus L3 RNAs used in this experiment are shown. Black boxes indicate the positions of UUUUUAU and AAUAAA. (B.) Results. Each lane contains RNA from one oocyte. $-41 /-1$ adenovirus L3 RNA containing either AAUAAA (lanes 1-3) or AAGAAA (lanes 4-6) was injected into the oocyte cytoplasm. Oocytes were then incubated for $12 \mathrm{hr}$ in either the presence $(+\mathrm{P})$ or absence $(-\mathrm{P})$ of progesterone. (Lane 1) AAUAAA-containing RNA that has not been injected; (lane 2) AAUAAAcontaining RNA injected, no progesterone; (lane 3) AAUAAAcontaining RNA injected, progesterone added; (lane 4) AAGAAA-containing RNA that has not been injected; (lane 5) AAGAAA-containing RNA injected, no progesterone; (lane 6) AAGAAA-containing RNA injected, progesterone added.

virus L3 mRNA (Moore and Sharp 1985), which possesses both sequences, by chance, should be a competent substrate even though it is not naturally present in frog oocytes. To test this prediction, we injected a 65 -nucleotide, $-41 /-1$ L3 RNA into the oocyte cytoplasm (Fig. 7). In this RNA, the UUUUUAU sequence is downstream of AAUAAA, not upstream, as in both D7 mRNA (Table 1) and the UUUUUAU-containing SV40 RNAs (Figs. 5 and 6).

In the absence of progesterone, L3 RNA receives $\sim 10$ nucleotides, which we presume are adenosine (Fig. 7, lane 1 versus lane 2). This presumptive oligoadenylation is similar to that seen in Figure 6 but is detected more readily here because the RNA is shorter. More importantly, in the presence of progesterone, a long poly(A) tail is added (Fig. 7, lane 3). This is confirmed by oligo(dT)-cellulose chromatography (not shown). Adenovirus L3 RNA containing AAGAAA does not receive long poly(A) in the presence of progesterone (Fig. 6, lane 4 versus lane 6), nor does it receive oligo(A) efficiently in its absence (Fig. 6, lane 4 versus lane 5). We conclude that UUUUUAU and AAUAAA are sufficient for the addition of poly(A) during maturation and that the relative positions of these two sequence elements are not critical.

The time at which polyadenylation activity appears during maturation relative to nuclear breakdown

The nucleus (germinal vesicle) breaks down during oocyte maturation. This event can be monitored by the appearance of a white spot at the animal pole of the oocyte. To determine when the maturation-specific polyadenylation activity appears relative to germinal vesicle breakdown (GVBD), we performed the following experiment. Approximately 100 oocytes were injected with D7 RNA; progesterone was then added to initiate maturation. At various times thereafter, RNA was prepared from 10 separate oocytes. The fraction of oocytes displaying polyadenylation activity was determined by electrophoresis of each RNA preparation, whereas the fraction of oocytes that had undergone nuclear breakdown was monitored by the appearance of the white spot. To minimize statistical variation attributable to the small sample size at each time point ( 10 oocytes), we selected 10 oocytes that accurately reflected the overall fraction of oocytes that had matured by that time. For example, at $5.5 \mathrm{hr}, 40 \%$ of the oocytes had white spots; therefore, we analyzed four oocytes with white spots and six without. The data are presented in Figure 8, in which the fraction of oocytes exhibiting any polyadenylation is plotted versus time after injection. The fraction of oocytes with a white spot is plotted for comparison.

The activity that polyadenylates D7 first appears 4.5 hr after injection, at approximately the same time as GVBD is first detected (Fig. 8). Five and one-half hours after progesterone treatment, activity is detected in $60 \%$ of the oocytes and $40 \%$ have undergone GVBD. By $9 \mathrm{hr}$, $80 \%$ have detectably undergone nuclear breakdown and $100 \%$ have polyadenylated the injected RNA.

At every time point, any oocyte that had undergone nuclear breakdown, as indicated by a white spot at the animal pole, also exhibited polyadenylation activity. For example, at $4.5 \mathrm{hr}$, the single oocyte with a white spot was the only oocyte with activity.

We conclude that the polyadenylation first appears within $1 \mathrm{hr}$ of GVBD. In particular, it clearly does not appear either immediately after progesterone treatment or substantially after nuclear breakdown.

\section{Removal of the nucleus does not prevent maturation- specific polyadenylation}

One possible explanation for the appearance of activity at approximately the time of GVBD is that polyadenylation activity requires both nuclear and cytoplasmic factors; in this hypothesis, the mixing of the nucleoplasm with the cytoplasm triggers polyadenylation. To test this proposal, we determined whether any nuclear component is required by analyzing polyadenylation in oocytes from which the nucleus had been manually removed. Oocytes were enucleated, injected with labeled 


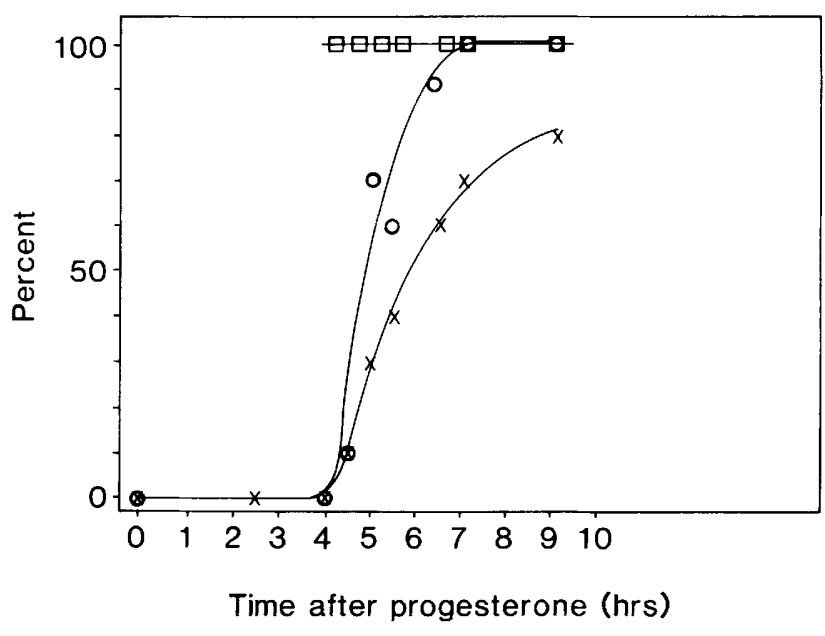

Figure 8. The time at which polyadenylation activity appears during maturation relative to nuclear breakdown. $-242 /+1 \mathrm{D} 7$ RNA was injected into the cytoplasm of $\sim 100$ oocytes, which were then incubated in the presence of progesterone. Maturation was monitored by the appearance of a white spot at the animal pole. At various times later, indicated on the $x$ axis, RNA was analyzed from 10 oocytes. To avoid error because of the small size of the sample at each time point (just 10 oocytes), these 10 oocytes were selected to represent the fraction of oocytes in the total batch that had a white spot at that time / see text for details). (O) Percentage of 10 oocytes that have polyadenylation activity; $(x)$ percent of the same 10 oocytes with a white spot; $(\square)$ percentage of those oocytes with a white spot that also display polyadenylation activity.

$-242 /+1$ D7 RNA, and treated with progesterone. As a control, oocytes that had been mock-enucleated /see Materials and methods) were analyzed in parallel. The results are shown in Figure 9A.

Both enucleated (lanes 3 and 4) and nonenucleated (lanes 7 and 8) oocytes exhibit polyadenylation activity after progesterone treatment. The level of activity is very similar with or without the nucleus. In the absence of progesterone, neither enucleated nor nonenucleated oocytes display activity (Fig. 9A, lanes 1 and 2, 5 and 6). We conclude that removal of the nucleus does not prevent maturation-induced polyadenylation.

The logical inference that nuclear components are not required for maturation-specific polyadenylation assumes that no nuclear components leak into the cytoplasm during the enucleation procedure. To test this assumption, we examined the distribution of U4 snRNA, which normally is exclusively nuclear, by Northern blotting to RNA from enucleated or intact oocytes (Fig. 9B). The somatic follicle cells that surround the oocyte contain U4 RNAs that differ in electrophoretic mobility from the oocyte's U4 RNA, and so provide a standard against which to compare the amount of the oocyte species (Lund and Dahlberg 1987). We readily detect 'oocyte' U4 RNA in intact oocytes (Fig. 9B, lanes 3 and 4) but fail to detect it in the 'cytoplasms' left after enucleation (Fig. 9B, lanes 1 and 2). Rather, the U4 RNA is found in the nuclei that have been removed (not shown). We infer that the enucleation method has not led to signifi- cant general leakage of nuclear components into the cytoplasm. We cannot exclude the possibility that a small fraction of the nuclear contents have escaped. With that proviso, we conclude that nuclear components are not required for maturation-induced polyadenylation.

\section{Discussion}

In this report we have shown that poly(A) addition to maternal mRNAs during oocyte maturation is biochemically distinct from poly(A) addition to nuclear premRNAs after cleavage. The two activities differ in substrate specificity and subcellular location. Whereas polyadenylation of pre-mRNAs requires only AAUAAA and is exclusively nuclear, polyadenylation of maternal mRNAs during maturation requires both AAUAAA and UUUUUAU and appears to involve no nuclear component.

\section{UUUUUAU and AAUAAA}

UUUUUAU and AAUAAA are both necessary (Figs. 5 and 6; McGrew et al. 1989) and virtually sufficient (Fig. 7) for poly(A) addition during maturation. Because all mRNAs contain AAUAAA, UUUUUAU distinguishes those mRNAs that receive poly(A) during maturation

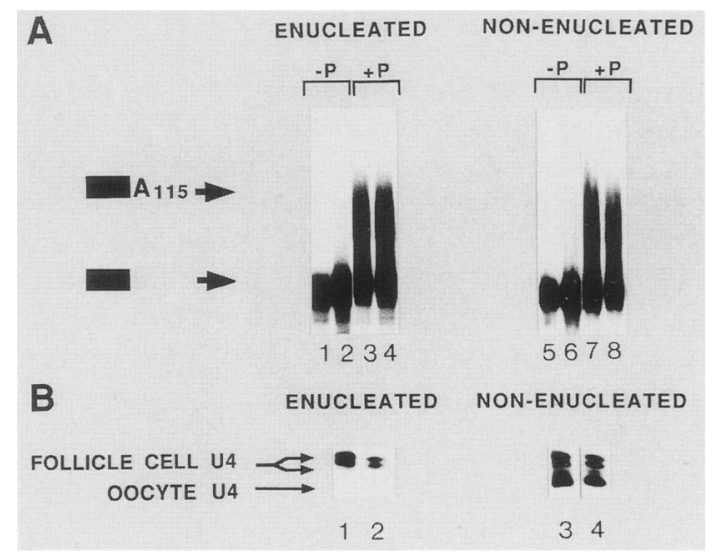

Figure 9. Removal of the nucleus does not prevent maturation-specific polyadenylation. (A) Analysis of injected RNA $-242 /-1$ D7 RNA was injected into the cytoplasm of either enucleated (lanes 1-4) or nonenucleated oocytes (lanes 5-8). Each lane contains RNA from one oocyte. (Lanes 1 and 2) Enucleated oocytes incubated without progesterone; (lanes 3 and 4) enucleated oocytes incubated in the presence of progesterone; (lanes 5 and 6) nonenucleated oocytes incubated without progesterone; (lanes 7 and 8 ) nonenucleated oocytes incubated in the presence of progesterone. $(B)$ Distribution of U4 snRNA after enucleation. RNA from enucleated (lanes 1 and 2) and nonenucleated (lanes 3 and 4) oocytes was assayed for the presence of U4 snRNA by Northern blotting (for details, see Materials and methods). Both enucleated and nonenucleated oocytes are surrounded by follicle cells and therefore contain the follicle-cell-specific U4, as well as the oocyte U4. (Lane 1) RNA from four enucleated oocytes; (lane 2) RNA from two enucleated oocytes; (lane 3) RNA from four nonenucleated oocytes; (lane 4) RNA from two nonenucleated oocytes. 
from those that do not. In that sense, the UUUUUAU sequence regulates polyadenylation during maturation.

Xenopus maternal mRNAs that receive poly(A) during maturation commonly contain UUUUUAU or a closely related sequence near AAUAAA, sometimes in multiple copies (Table 1; McGrew et al. 1989). In each of the natural mRNAs listed in Table 1, the UUUUUAU sequence is upstream of AAUAAA; however, our results suggest that the relative position of the two sequences is not critical (Fig. 7). Further experiments will be required to determine whether a variant sequence, such as the UUUUUAAU in B4 mRNA, can support polyadenylation.

Paradoxically, D7 RNA contains AAUAUA, yet is polyadenylated during maturation. We infer that other sequences in D7 compensate for the lack of a consensus AAUAAA, particularly because the requirement for AAUAAA is not only observed in the artificial, SV40-derived RNAs that we used but also in naturally occurring 3'-untranslated regions (McGrew et al. 1989; J.-D. Vassalli et al. 1989|. Furthermore, our results with SV40-derived RNAs demonstrate that sequences between UUUUUAU and AAUAAA can influence the efficiency with which SV40-derived RNAs receive poly(A) (Fig. 5 versus Fig. 6). Regardless, D7's lack of a canonical AAUAAA explains its failure to receive poly(A) in the nucleus: After injection into the nucleus, SV40 RNAs containing AAUAUA do not receive poly(A), whereas RNAs containing UUUUUAU and AAUAAA do (not shown).

Polyadenylation during maturation does not require translation of the RNA substrate. In all of our experiments, we injected short RNA fragments comprising only portions of the $3^{\prime}$-untranslated regions of mRNAs. These RNAs can be as short as 65 nucleotides and contain no significant open reading frame for translation. Similarly, the natural mRNA substrates probably are not associated with polyribosomes.

\section{Mechanism of polyadenylation during maturation: analogies to nuclear polyadenylation}

In a HeLa cell nuclear extract, the addition of a fulllength $\operatorname{poly}(\mathrm{A})$ tail proceeds in two distinct phases (Sheets and Wickens 1989). In the first phase, each polymerization step requires AAUAAA; in the second, an oligo(A) segment is required, but AAUAAA is dispensable. The transition between phases occurs with the addition of the tenth adenosine.

Addition of poly(A) to maternal mRNAs during maturation may be analogous to the onset of the second phase of nuclear polyadenylation. In the absence of progesterone, $\sim 10$ nucleotides are added to injected substrates that end at the poly(A) site. This is seen most clearly with the shortest substrate used, adenovirus L3 RNA (Fig. 7). The 10 nucleotides presumably are adenosines, as AAUAAA is required for their addition. By analogy to the nuclear reaction, the addition of long poly(A) during maturation could be attributable to activation of a second phase of synthesis, in which the short poly(A) segment is recognized. Alternatively, progesterone treatment may accelerate the rate of polymerization, rather than cause the onset of a discrete second phase of synthesis. This alternative hypothesis is more readily reconciled with the fact that some mRNAs that receive poly(A) already have poly(A) tails longer than 10 nucleotides before maturation begins (e.g., Dworkin and Dworkin-Rastl 1985; Dworkin et al. 1985). Whatever the mechanism of activation, however, the observation that an AAUAAA-dependent polymerization reaction occurs in the cytoplasm before maturation strongly suggests that some, if not all, of the factors that catalyze polyadenylation during maturation are present in the cytoplasm before progesterone treatment.

The precise mechanisms used to recognize and polyadenylate different maternal mRNAs may not be identical because the length of poly(A) that they contain before maturation varies substantially. For example, G10 mRNA contains a poly(A) tail of $\sim 90$ nucleotides, whereas D7 mRNA appears to contain a poly(A) tail of 15 nucleotides or less, as judged by its inefficient retention on oligo(dT)-cellulose (Dworkin and Dworkin-Rastl 1985; Dworkin et al. 1985). However, because both mRNAs contain UUUUUAU (e.g., McGrew et al. 1989), the mechanisms by which they receive poly(A) during maturation probably share critical features.

In vivo, addition of short poly(A) tails to endogenous mRNAs may require AAUAAA and occur in the cytoplasm during oogenesis. This is consistent with our observation that in the absence of progesterone, AAUAAA is needed to add short tails to RNAs that end at the poly(A) site. The addition of long poly(A) to authentic maternal mRNAs during maturation might require only UUUUUAU and these short tails and not AAUAAA per se.

In nuclear extracts, the poly $(\mathrm{A})$ polymerase gains specificity for mRNAs by interacting with a distinct specificity factor (Takagaki et al. 1988; Christofori and Keller 1989 ) that probably binds to AAUAAA (P. Wigley et al., in prep.). By analogy, the cytoplasmic reaction may also involve separable polymerase and sequence-specificity components. Cytoplasmic specificity factors, specific for UUUUUAU or the oligo(A) primer, might stimulate the polymerase to recognize only the appropriate maternal mRNAs as substrates. Poly(A) polymerases that fractionate in the cytoplasmic fraction of cell homogenates have long been reported, though their function and subcellular distribution in vivo are not known (see Ryner et al. 1989, Edmonds, in press).

\section{A possible role of polyadenylation during maturation}

Addition of poly(A) to a maternal mRNA during maturation may cause mRNA to be translated. A correlation between an increase in the length of poly(A) on a specific maternal mRNA and an increase in that mRNA's translation is common (e.g., Rosenthal et al. 1983; Dworkin and Dworkin-Rastl 1985; Dworkin et al. 1985; Huarte et al. 1987; Rosenthal and Ruderman 1987), though not universal (Ruderman et al. 1979; Rosenthal et al. 1983; 
Rosenthal and Ruderman 1987). As suggested by McGrew et al. (1989), translational activation of maternal mRNAs may not be due simply to them acquiring a certain minimal length of poly(A), but, rather, to the 'dynamic' polyadenylation process. Regardless, several distinct lines of evidence directly suggest that poly(A) enhances translation initiation. For example, poly(A) tails are required for efficient translation of synthetic mRNAs, both in vitro and in frog oocytes (Jacobson and Favreau 1983; Drummond et al. 1985; Galili et al. 1988; D. Munroe and A. Jacobson, in press). Inhibiting polyadenylation of a specific maternal mRNA during maturation of both frog and mouse oocytes decreases the recruitment of that mRNA onto polysomes (Strickland et al. 1988; McGrew et al. 1989). In yeast, lack of poly(A)binding protein, which is likely to be functionally equivalent to lack of poly(A), impairs translation and can be compensated for by a mutation in ribosomal protein L 46 (Sachs and Davis 1989).

A critical function of polyadenylation during maturation may be to activate translation of mRNAs that are critical for maturation to proceed. The addition of poly|A) during maturation occurs within $1 \mathrm{hr}$ of GVBD (Fig. 8), yet is unlikely to be triggered by the mixing of nuclear and cytoplasmic factors, as it is unimpaired by enucleation (Fig. 9). A single cytoplasmic event, initiated by progesterone, could independently cause polyadenylation and nuclear breakdown. Alternatively, polyadenylation might be required for nuclear breakdown. We find this alternative hypothesis attractive, as it is consistent with several disparate observations. First, injection of $3^{\prime}$ deoxyadenosine into frog oocytes, which presumably prevents polyadenylation of endogenous mRNAs during maturation, blocks nuclear breakdown (McGrew et al. 1989). Conversely, injection of poly(A)-containing RNA from eggs, but not from oocytes, promotes maturation (Pines and Hunt 1987). Second, appearance of MPF (maturation-promoting activity), which is required for maturation, requires translation during maturation (Gerhart et al. 1984). Likewise, the D7 protein product, which also is required for efficient nuclear breakdown (Smith et al. 1988), is activated for translation during maturation, when it receives poly(A) (Dworkin and Dworkin-Rastl 1985). Third, at least three mRNAs encoding proteins known to be involved in maturationcyclin B2 (Minshull et al. 1989), c-mos (Sagata et al. 1989b), and D7 (Smith et al. 1988) - contain both UUUUUAU (or UUUUAU) and AAUAAA in close proximity and are translationally activated during maturation (Table 2). Although these mRNAs have not been directly shown to undergo poly(A) addition during maturation in Xenopus, the common correlation between polyadenylation and translation suggests that they may do so. Furthermore, in eggs of other animal species, cyclin mRNAs concurrently are activated for translation and receive poly(A) (e.g., Standart et al. 1987). In sum, combining our results with those of others, we suggest that polyadenylation may be one of a series of dependent steps in the pathway that promotes maturation. This need not be the sole function of poly(A) addition during maturation, nor is it likely to be the only way to activate translation of maternal mRNAs.

The models proposed here lead to testable predictions concerning both the mechanism of poly $(\mathrm{A})$ addition and its role in maturation. It will be of interest to determine how polyadenylation of maternal mRNAs is catalyzed and regulated and how the addition of the tail facilitates translational activation. It should be possible to address these problems by combining oocyte microinjection with the general approaches that have proved effective in revealing the mechanism of poly $(\mathrm{A})$ addition in the nucleus.

\section{Materials and methods}

Plasmid construction and structure of RNA substrates

All plasmids are named by the sequences that they contain. The poly(A) site is designated as +1 . Thus, pSPSV $-58 /+70$ contains 58 nucleotides before and 70 nucleotides after the polyadenylation site of SV40 late mRNAs, cloned into an SP6 transcription vector.

$-141 /-1$ SV40 RNA To construct pSPSV - 141/-1, pSPSV $-141 /+70$ (Zarkower and Wickens 1987) was digested with HindIII, which cleaves at +70 . This digest was treated with BAL-31 exonuclease. $X b a \mathrm{I}$ linkers (CTCTAGAG) were ligated to the new ends. pSPSV $-141 /-1$ contains a $X b a I$ linker following the $-1 \mathrm{C}$ of SV40 late mRNAs. To prepare $-141 /-1$ SV40 RNA, the DNA was cleaved with $X b a I$ and transcribed with SP6 polymerase. pSPSV $-141 /-1$ SV40 RNA contains 26 nucleotides of vector sequence, followed by 140 nucleotides of SV40 and 6 nucleotides of the $X b a I$ linker.

$-58 /+7$ SV40 RNA containing either AAUAAA or AAGAAA pSPSV $-58 /+70$ containing AAUAAA or AAGAAA were generated as described (Sheets and Wickens 1989). To prepare $-58 /+7$ SV40 RNA, the DNA was digested with BsmI, treated with T4 DNA polymerase to remove single-stranded overhangs, and transcribed with SP6 polymerase. $-58 /+7$ SV40 RNA contains 12 nucleotides of vector sequence, followed by 65 nucleotides of SV40 sequence.

Table 2. mRNAs encoding proteins that promote maturation of Xenopus oocytes

\begin{tabular}{ll}
\hline mRNA & Sequence \\
\hline cyclin B2 & uaau g u c a g u a u g a AAUAAAcuucacauUUUUUAUuu-poly(A) \\
c-mos & auau a u a g UUUUAUAAUAAAga aauuga u u u g c c u-poly(A) \\
D7 & a gcUUUUUAU c a c a AAUAUAauacuaau u a c u u g a auguauuuguuacc-poly(A) \\
\hline
\end{tabular}

Sequences are taken from the following publications: cyclin B2, Minshull et al. (1989); c-mos, Sagata et al. (1988); D7, Smith et al. (1988). 
$-242 /+1$ SV40 RNA pSPD7 -242/+1 was generated by cloning the 3 '-most HincII fragment of D7 cDNA (Smith et al. 1988) into the HincII site of pGem3Z. This template was cleaved with $X b a I$ and transcribed with SP6 polymerase. $-242 /+1$ D7 RNA contains 26 nucleotides of vector sequence, followed by 243 nucleotides of D7 sequence and 8 nucleotides of vector sequence.

-141/-1 SV40 RNAs containing insertions of UUUUUAU or point mutations in AAUAAA Templates used to synthesize these RNAs were derived from pSPSV $-141 /-1$ by oligodeoxynucleotide-directed mutagenesis (Kunkel 1985). Two clones were prepared to direct the synthesis of UUUUUAU-containing RNAs (Figs. 5 and 6). In the first clone (Fig. 5), three nucleotides $(-32$ to -30$)$ have been changed from CCA to TTT. In the second (Fig. 6), the SV40 sequence from -33 to - 19 (ACCATTATAAGCTGC) has been changed to CTTTTTATCTAGTC. To prepare SV40 RNAs containing UUUUUAU, the appropriate DNA was digested with $X b a I$ and transcribed with SP6 polymerase. Both DNAs direct the synthesis of SV40 RNAs containing UUUUUAU; the second RNA (Fig. 6) also contains changes between this UUUUUAU and AAUAAA. These were introduced to facilitate subsequent cloning manipulations. Both RNAs produced are identical to $-141 /-1$ SV40 RNA but for the regions mentioned previously. The sequences of the last 41 nucleotides of these RNAs are presented in Figures 5A and 6A.

Mutations in AATAAA (Fig. 6) were also generated by oligonucleotide-directed mutagenesis (Kunkel 1985), using pSPSV $-141 /-1$ DNA. The sequence of the last 41 nucleotides of each RNA is presented in Figure 6A.

-41/-1 Adenovirus L3 RNA containing either AAUAAA or $A A G A A A$ pSPGL3-pre and pSP6L3-pre-1 /this template carries the AAGAAA mutation/ were constructed as described (Christofori and Keller 1989). To prepare $-41 /-1$ L3 RNA, DNA was digested with RsaI and transcribed with SP6 polymerase. $-41 /-1$ L3 RNA contains 24 nucleotides of vector sequences, followed by 41 nucleotides of adenovirus $\mathrm{L} 3$ sequence, ending 1 nucleotide before the natural poly(A) site.

\section{Preparation of RNA substrates}

SP6 polymerase was incubated with cleaved DNA in the presence of $\sim 200 \mu \mathrm{Ci}$ [32P]UTP and $\mathrm{m}^{7} \mathrm{GpppG}$ (Melton et al. 1984). UTP ( $100 \mu \mathrm{M}$; unlabeled) was also present. Transcriptions were carried out in a volume of $10 \mu \mathrm{l}$. Transcripts of the appropriate length were eluted from a polyacrylamide gel slice, as described (Maxam and Gilbert 1980). The eluate was extracted with phenol/chloroform twice, and the aqueous layer was precipitated with ethanol. The precipitate was redissolved in water and reprecipitated. This was repeated twice. The final precipitate was redissolved in $88 \mathrm{mM} \mathrm{NaCl}$ at an approximate concentration of $100 \mathrm{fmole} / \mu \mathrm{l}$.

To prepare substrates with oligo(A) tails, $-58 /+7$ SV40 RNAs were treated with Escherichia coli poly(A) polymerase, as described (Sheets and Wickens 1989).

\section{Oocyte injections}

Oocyte microinjection and micromanipulation were performed essentially as described (Wickens and Gurdon 1983). Ten to 20 separate oocytes were used for each assay. RNA was analyzed from each individual oocyte to assess oocyte-to-oocyte variation and failure to inject into the nucleus.
Nuclear injections Single oocytes in either MBS (Gurdon and Wickens 1983) or MR medium (Gerhart et al. 1984) were placed on a plastic screen grid in a petri dish and centrifuged for 10 min in a Sorvall RT6000 centrifuge at $1400 \mathrm{rpm}$; this brings nuclei to the cortex. Five to ten nanoliters of a solution containing 0.5 to 1 fmole of RNA at a sp. act. of $12,000-22,000$ $\mathrm{cpm} / \mathrm{fmole}$, was microinjected into the oocyte nucleus. Injected oocytes were incubated for $30 \mathrm{~min}$ at $20^{\circ} \mathrm{C}$ in either MBS or MR media.

Cytoplasmic injections Twenty-five to fifty nanoliters of a solution containing 2.5 to 5 fmoles of RNA at a sp. act. of $22,000 \mathrm{cpm} / \mathrm{fmole}$, was microinjected into the oocyte cytoplasm. Injected oocytes were incubated for $8-12 \mathrm{hr}$ at $20^{\circ} \mathrm{C}$ in MR media in the presence or absence of $1 \mu \mathrm{g} / \mathrm{ml}$ progesterone. Of those oocytes incubated with progesterone, only those with a white spot were analyzed (except in the experiment shown in Fig. 7 . In general, $70-100 \%$ of oocytes exposed to progesterone displayed a white spot.

\section{Extraction and analysis of RNA}

Each oocyte was homogenized in $200 \mu$ l of $50 \mathrm{~mm}$ Tris (pH 7.9), $5 \mathrm{~mm}$ EDTA, $2 \%$ SDS, $300 \mathrm{~mm} \mathrm{NaCl}$, and $250 \mu \mathrm{g} / \mathrm{ml}$ of proteinase $\mathrm{K}$. The homogenate was extracted with phenol/chloroform, and the aqueous phase was precipitated with ethanol. Each RNA pellet was resuspended in $10 \mu \mathrm{l}$ of water and analyzed by electrophoresis through $6 \%, 10 \%$, or $15 \%$ polyacrylamide gels containing $7 \mathrm{M}$ urea (Sanger and Coulson 1978). Oligo(dT)-cellulose chromatography was performed as described (Zarkower et al. 1986). Autoradiographic exposures of the dried gels were generally for 6-24 hours with an intensifying screen.

\section{Enucleation of oocytes}

Individual oocytes were placed in a petri dish and pricked with a fine injection needle at the animal pole. The oocyte was then gently squeezed with watchmaker's forceps until the first appearance of the nucleus. After approximately $5 \mathrm{~min}$, the nucleus was separated from the oocyte by gently shaking the petri dish until the nucleus floated away. For mock enucleations, oocytes were pricked near the equator. In both real and mock enucleations, after pricking, oocytes were allowed to heal for $4 \mathrm{hr}$ in MR buffer. Oocytes that appeared damaged after $4 \mathrm{hr}$ were discarded. The rest were either injected with radiolabeled RNA or analyzed for U4 RNA. Six to 10 individual enucleated oocytes and control oocytes were analyzed for polyadenylation for each experiment.

\section{Detection of U4 RNA}

RNA from enucleated or mock-enucleated oocytes was isolated as described above. Six to 16 oocytes of both types were analyzed for U4 RNA in each experiment. Electrophoresis, electroblotting, and the U4 hybridization probe were as described (Lund and Dahlberg 1987), except that Zeta-probe nylon membranes (Bio-Rad Laboratories) were used. Hybridizations were performed in $50 \%$ formamide, $1.5 \times$ SSPE, $1 \%$ SDS, $0.5 \mathrm{~g} / \mathrm{ml}$ of nonfat powdered milk, $0.01 \%$ sodium azide, and $0.5 \mathrm{mg} / \mathrm{ml} \mathrm{car-}$ rier DNA at $52^{\circ} \mathrm{C}$ for $12-16 \mathrm{hr}$. After hybridization, blots were washed at $55^{\circ} \mathrm{C}$ in $2 \times$ SSC containing $0.1 \%$ SDS for $15-$ $0 \mathrm{~min}$, and then in $0.5 \times$ SSC containing $0.1 \%$ SDS for $15-30$ $\mathrm{min}$. Autoradiographic exposures, with an intensifying screen, were carried out for 2-6 days. 


\section{Nucleotide sequence of $\mathrm{H} 4 \mathrm{mRNA}$}

H4 cDNA (Dworkin and Dworkin-Rastl 1985) was a generous gift of Drs. Dworkin and Dworkin-Rastl. For sequencing, an EcoRI-HindIII fragment of their H4 cDNA (pMW005) was cloned into the EcoRI and HindIII sites of pGem3Z. The sequence of both strands of the insert was determined by the chain termination method (Sanger and Coulson 1978), using SP6 and T7 primers. The position of the poly(A) site was inferred from the position of the poly(dA) tract in the cDNA.

\section{Acknowledgments}

We are particularly grateful to Joel Richter and his colleagues for communication of their results on the polyadenylation of G10 mRNA prior to publication and to Mark Dworkin, Eva Dworkin-Rastl, and their colleagues for generously providing us with several cDNA clones, including the D7 and $\mathrm{H} 4$ clones described here. We thank Alan Sachs and Alan Jacobson for sharing their results and thoughts on poly(A) and translation prior to publication. Elsebet Lund was very helpful in providing reagents and advice for the experiment in Figure 9. Gerhart Christofori and Walter Keller generously provided the adenovirus L3 template. We are very grateful to Phil Anderson, Jim Dahlberg, Richard Harland, Judith Kimble, and Joan Ruderman for helpful comments on the manuscript. Discussion with members of the Wickens laboratory was valuable and is appreciated. We especially thank Pete Wigley for help with mutagenesis. Mary Whitmer, Laura Vanderploeg, and Jim Becker were very generous and helpful in assembling figures. DNA oligonucleotide synthesis was performed by the protein sequence-DNA Synthesis Facility, supported by the U.S. Public Health Service, the National Institutes of Health (NIH) (S10RR01684 and CA-07107), a GRS grant to the University of Wisconsin, Medical School, and by the University of Wisconsin Graduate School. The research was supported by WARF and National Sciences Foundation predoctoral fellowships to C.F., by a University of Wisconsin Cell and Molecular Biology Training Grant fellowship to M.S., and by an NIH research grant (GM31892) and Research Career Development Award (GM00521) to M.W.

\section{References}

Bachvarova, R., V. DeLeon, A. Johnson, G. Kaplan, and B.V. Paynton. 1985. Changes in total RNA, polyadenylated RNA and actin mRNA during meiotic maturation of mouse oocytes. Dev. Biol. 108: 325-331.

Bardwell, V. and M. Wickens. Polyadenylation-specific complexes undergo a transition early in the polymerization of a poly(A) tail. Mol. Cell Biol. (in press).

Bardwell, V., D. Zarkower, M. Edmonds, and M. Wickens. 1990. The enzyme that adds poly(A) to mRNAs is a classical poly(A) polymerase (in press).

Christofori, G. and W. Keller. 1988. 3' Cleavage and polyadenylation of mRNA precursors in vitro require a poly (A) polymerase, a cleavage factor, and a snRNP. Cell 54: 875-889.

- 1989. Poly(A) polymerase purified from HeLa cell nuclear extract is required for both cleavage and polyadenylation of pre-mRNA in vitro. Mol. Cell. Biol. 9: 193-203.

Colot, H.V. and M. Rosbash. 1982. Behavior of individual maternal pA + RNAs during embryogenesis of Xenopus laevis. Dev. Biol. 94: 79-86.

De Robertis, E.M. and J.E. Mertz. 1977. Coupled transcription- translation of DNA injected into Xenopus oocytes. Cell 12: $175-182$.

Drummond, D.R., J. Armstrong, and A. Coleman. 1985. The effect of capping and polyadenylation on the stability. movement, and translation of synthetic messenger RNAs in Xenopus oocytes. Nucleic Acids Res. 13: 7375-7392.

Dworkin, M.B. and E. Dworkin-Rastl. 1985. Changes in RNA titers and polyadenylation during oogenesis and oocyte maturation in Xenopus laevis. Dev. Biol. 112: 451-457.

Dworkin, M.B., A. Shrutkowski, and E. Dworkin-Rastl. 1985. Mobilization of specific maternal mRNA species into polysomes after fertilization in Xenopus laevis. Proc. Natl. Acad. Sci. 82: 7636-7640.

Edmonds, M. 1989. poly(A) polymerases. In Methods in Enzymology. (ed. J. Abelson, and J. Dahlberg), Academic Press, New York.

Fradin, A., R. Jove, C. Hemenway, H.D. Keier, J.L. Manley, and C. Prives. 1984. Splicing pathways of SV40 mRNA in $X$. laevis oocytes differ in their requirements for snRNPs. Cell 37: 927-936.

Galili, G., E.E. Kawata, L.D. Smith, and B.A. Larkins. 1988. Role of the 3'-poly(A) sequence in translational regulation of mRNAs in Xenopus laevis oocytes. I. Biol. Chem. 263: $5764-5770$.

Gerhart, J.C., M. Wu, and M. Kirschner. 1984. Cell cycle dynamics of an $M$-phase specific cytoplasmic factor in Xenopus laevis oocytes and eggs. I. Cell Biol. 98: 12471255.

Gerhart, J.C. 1988. Mechanisms regulating pattern formation in the amphibian egg and early embryo. In Biological regulation and development, vol. 2, pp. 145-180, Plenum Press, New York.

Gick, O., A. Kramer, W. Keller, and M. L. Birnstiel. 1986. Generation of histone mRNA 3 ' ends by endonucleolytic cleavage of the pre-mRNA in a snRNP-dependent in vitro reaction. EMBO /. 5: 1319-1326.

Huarte, J., D. Belin, A. Vassalli, and S. Strickland. 1987. Meiotic maturation of mouse oocytes triggers the translation and polyadenylation of dormant tissue-type plasminogen activator mRNA. Genes Dev. 1: 1201-1211.

Humphries, T. and N.J Proudfoot. 1988. A beginning to the biochemistry of polyadenylation. Trends Genet. 4: 243-245.

Hyman, L.E. and M.W. Wormington. 1988. Translational inactivation of a ribosomal protein mRNA during Xenopus oocyte maturation. Genes Dev. 2: 598-605.

Jacobson, A. and M. Favreau. 1983. Possible involvement of poly(A) in protein synthesis. Nucleic Acids. Res. 18: 63536368.

Kunkel, T.A. 1985. Rapid and efficient site-specific mutagenesis without phenotypic selection. Proc. Natl. Acad. Sci. 82: $488-492$.

Lewin, B. 1980. Gene expression 2, 2nd ed. pp. 736-743, John Wiley and Sons, New York.

Lund, E. and J.E. Dahlberg, 1987. Differential accumulation of U1 and U4 small nuclear RNAs during Xenopus development. Genes Dev. 1: 39-46.

Manley, J.L. 1988. Polyadenylation of mRNA precursors. Biochim. Biophys. Acta 950: 1-12.

Maxam, A.M. and W. Gilbert. 1980. Sequencing end-labeled DNA with base-specific chemical cleavages. Methods Enzymol. 65: 499-560.

McDevitt, M.A., G.M. Gilmartin, W.H. Reeves, and J.R. Nevins. 1988. Multiple factors are required for poly(A) addition to a mRNA 3' end. Genes Dev. 2: 588-597.

McGrew, L.L., E. Dworkin-Rastl, M.B. Dworkin, and J.D. 
Richter. 1989. Poly(A) elongation during Xenopus oocyte maturation is required for translational recruitment and is mediated by a short sequence element. Genes Dev. 3: 803815.

Melton, D., P.A. Krieg, M.R. Rebagliati, T. Maniatis, K. Zinn, and M.R. Green. 1984. Efficient in vitro synthesis of biologically active RNA and RNA hybridization probes from plasmids containing a bacteriophage SP6 promoter. Nucleic Acids. Res. 12: 7035-7056.

Minshull, J., J.J. Blow, and T. Hunt. 1989. Translation of cyclin mRNA is necessary for extracts of Xenopus eggs to enter mitosis. Cell 56: 947-956.

Moore, C.L. and P.A. Sharp. 1985. Accurate cleavage and polyadenylation of exogenous RNA substrate. Cell 41: 845-855.

Moore, C.L., H. Skolnik-David, and P.A. Sharp. 1986. Analysis of RNA cleavage at the adenovirus- 2 L3 polyadenylation site. EMBO J. 5: 1929-1938.

Munroe, D. and A. Jacobsen. mRNA poly(A) tail: a 3' enhancer of translation initiation (in prep.).

Nevins, J.R. and J.E. Darnell. 1978. Steps in the processing of adenovirus 2 mRNA: Poly $(\mathrm{A})^{+}$nuclear sequences are conserved and poly(A) addition precedes splicing. Cell 15: $1477-1493$.

Paynton, B.V., R. Rempel, and R. Bachvarova. 1988. Changes in the state of adenylation and time course of degradation of maternal mRNAs during oocyte maturation and early embryonic development in the mouse. Dev. Biol. 129: 304314.

Pines, T. and T. Hunt. 1987. Molecular cloning and characterization of the mRNA for cyclin in sea urchin eggs. EMBO $J$. 6: $2987-2995$.

Rosenthal, E. and J.V. Ruderman. 1987. Widespread changes in the translation and adenylation of natural messenger RNAs following fertilization of Spisula oocytes. Dev. Biol. 121: $237-246$.

Rosenthal, E.T., T.R. Tansey, and J.V. Ruderman. 1983. Sequence-specific adenylations and deadenylation accompany changes in the translation of maternal messenger RNA after fertilization of Spisula oocytes. J. Mol. Biol. 166: 309-327.

Ruderman, J.V., H.R. Woodland, and E.A. Sturgess. 1979. Modulations of histone messenger RNA during early development of Xenopus laevis. Dev. Biol. 71: 71-82.

Ryner, L., Y. Takagaki, and J.L. Manley. 1989. Poly(A) polymerases from HeLa cell nuclear and cytoplasmic fractions function in specific mRNA $3^{\prime}$ end formation. Mol. Cell. Biol.

Sachs, A. and R. Davis, 1989. The poly(A) binding protein is required for poly(A) shortening and $60 \mathrm{~S}$ ribosomal subunit dependent translation initiation. Cell 58: 857-867.

Sagata, N, M. Oskarrson, T. Copeland, J. Brumbaugh, and G.F. Van de Woude. 1989b. Function of c-mos proto-oncogene product in meiotic maturation in Xenopus oocytes. Nature 338: $519-525$.

Sanger, F. and A. Coulson. 1978. The use of thin acrylamide gels for DNA sequencing. FEBS Lett. 87: 107-110.

Sheets, M. and M. Wickens. 1989. Two phases in the addition of a poly(A) tail. Genes Dev. 3: 1401-1412.

Sheets, M.D., P. Stephenson, and M. Wickens. 1987. Products of in vitro cleavage and polyadenylation of Simian Virus 40 late pre-mRNAs. Mol. Cell. Biol. 7: 1518-1529.

Sheiness, D. and J.E. Darnell. 1973. Poly(A) segment in mRNA becomes shorter with age. Nat. New Biol. 241: 265-268.

Smith, R.C., M.B. Dworkin, and E. Dworkin-Rastl. 1988. Destruction of a translationally controlled mRNA in Xenopus oocytes during progesterone-induced maturation. Genes Dev. 2: 1296-1306.
Staudart, N., J. Minshull, J. Pines, and T. Hunt. 1987. Cyclin synthesis, modification and destruction during meiotic maturation of the starfish oocyte. Dev. Biol. 124: 248-258.

Strickland, S., J. Huarte, D. Belin, A. Vassalli, R.J. Rickels, and J.D. Vassalli. 1988. Antisense RNA directed against the $3^{\prime}$ noncoding region prevents dormant mRNA activation in mouse oocytes. Science 241: 680-684.

Takagaki, Y., L.C. Ryner, and J.L. Manley. 1988. Separation and characterization of a poly (A) polymerase and a cleavage/ specificity factor required for pre-mRNA polyadenylation. Cell 52: 731-742.

Vassalli, J-D., J. Huarte, D. Belin, P. Gubler, A. Vassalli, M.L. O'Connell, L.A. Parton, R.J. Rickles, and S. Strickland. Regulated polyadenylation controls mRNA translation during meiotic maturation of mouse oocytes. Genes Dev. 2163-2171.

Wickens, M.P. and J.B. Gurdon. 1983. Post-transcriptional processing of Simian Virus 40 late transcripts in injected frog oocytes. J. Mol. Biol. 163: 1-26

Wickens, $M$. The mechanism and regulation of poly $(A)$ addition and removal. Trends in Bioch. Sci. (in prep.)

Wigley, P., M.D. Sheets, D.A. Zarkower, and M. Wickens. Submitted. Polyadenylation of mRNA: Minimal substrates and a requirement for the $2^{\prime}$ hydroxyl of the $U$ in AAUAAA. (in prep.)

Winters, M.A. and M. Edmonds. 1973. A poly(A) polymerase from calf thymus. J. Biol. Chem. 248: 4756-4762.

Zarkower, D. and M. Wickens. 1987. Formation of mRNA $3^{\prime}$ termini: Stability and dissociation of a complex involving the AAUAAA seqeunce. EMBO $J$. 6: 177-186.

Zarkower, D., P. Stephenson, M. Sheets, and M. Wickens. 1986. The AAUAAA sequence is required both for cleavage and for polyadenylation of Simian Virus 40 pre-mRNA in vitro. Mol. Cell. Biol. 6: 2317-2323. 


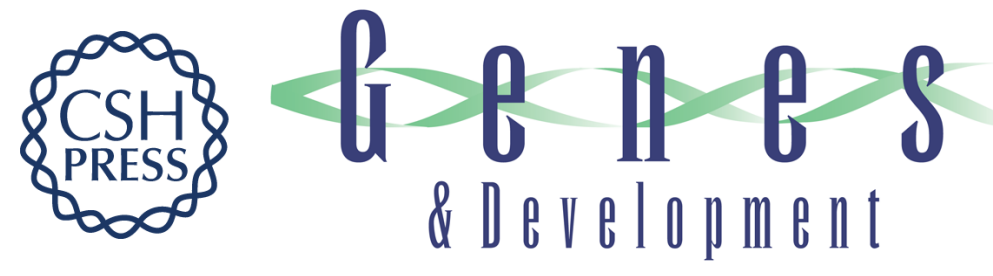

\section{$\operatorname{Poly}(\mathrm{A})$ addition during maturation of frog oocytes: distinct nuclear and cytoplasmic activities and regulation by the sequence UUUUUAU.}

C A Fox, M D Sheets and M P Wickens

Genes Dev. 1989, 3:

Access the most recent version at doi:10.1101/gad.3.12b.2151

References This article cites 46 articles, 16 of which can be accessed free at:

http://genesdev.cshlp.org/content/3/12b/2151.full.html\#ref-list-1

License

Email Alerting Service

Receive free email alerts when new articles cite this article - sign up in the box at the top right corner of the article or click here.

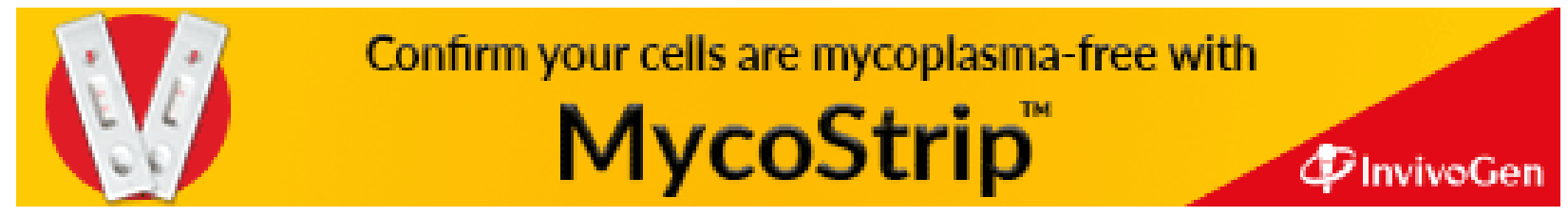

